\title{
Motives for mixing alcohol with energy drinks and other nonalcoholic beverages, and consequences for overall alcohol consumption
}

\author{
This article was published in the following Dove Press journal: \\ International Journal of General Medicine \\ 18 June 2014 \\ Number of times this article has been viewed
}

\section{Joris C Verster ${ }^{1,2}$ \\ Sarah Benson ${ }^{2}$ \\ Andrew Scholey ${ }^{2}$}

'Utrecht Institute for Pharmaceutical Sciences, Division of Pharmacology, Utrecht University, Utrecht, the Netherlands; ${ }^{2}$ Centre for Human Psychopharmacology, Swinburne University, Melbourne, VIC, Australia
Correspondence: Joris C Verster Division of Pharmacology, Utrecht Institute for Pharmaceutical Sciences, Utrecht University, Universiteitsweg 99. 3584CG, Utrecht, the Netherlands

$\mathrm{Tel}+3 \mathrm{I} 302536909$

Fax +31 302537900

Email j.c.verster@uu.nl
Introduction: The aim of this survey was to assess the motives for energy drink consumption, both alone and mixed with alcohol, and to determine whether negative or neutral motives for consuming alcohol mixed with energy drinks (AMED) have a differential effect on overall alcohol consumption.

Methods: Demographics, alcohol and energy drink consumption-related questions, and motives for the consumption of energy drinks (alone or mixed with alcohol) were assessed. The motives to mix alcohol with energy drinks were compared with those for mixing alcohol with other nonalcoholic beverages.

Results: A total of 2,329 students who completed the study consumed energy drinks. The motives for consuming energy drinks (without alcohol) included "I like the taste" (58.6\%), "To keep me awake" (54.3\%), "It gives me energy" (44.3\%), "It helps concentrating when studying" (33.9\%), "It increases alertness" (28.8\%), "It helps me concentrate better" (20.6\%), and "It makes me less sleepy when driving" (14.2\%). A total of 1,239 students reported occasionally consuming AMED (AMED group). The most frequent motives included "I like the taste" (81.1\%), "I wanted to drink something else" (35.3\%), and "To celebrate a special occasion" (14.6\%). No relevant differences in motives were observed for using an energy drink or another nonalcoholic beverage as a mixer. A minority of students $(21.6 \%)$ reported at least one negative motive to consume AMED. Despite these negative motives, students reported consuming significantly less alcohol on occasions when they consumed AMED compared to alcohol-only occasions.

Conclusion: The majority of students who consume energy drinks (without alcohol) do so because they like the taste, or they consume these drinks to keep them awake and give them energy. AMED consumption is more frequently motivated by neutral as opposed to negative motives. No relevant differences in drinking motives and overall alcohol consumption were observed between the occasions when energy drinks or other nonalcoholic beverages were mixed with alcohol.

Keywords: alcohol, energy drink, AMED, motives, consumption pattern, mixing

\section{Introduction}

Unless beverages provide a specific benefit, it is unlikely that they are consumed regularly if people dislike the taste. Since energy drinks provide additional benefits via their functional ingredients (for example, caffeine), these effects could serve as other important motives for consumption. For example, experimental research has shown that the consumption of energy drinks increases alertness and concentration. ${ }^{1-3}$ Hence, an important reason for consuming energy drinks may be to counteract sleepi- 
ness and to feel "energetic". The effects of energy drinks can include enhanced cognitive and psychomotor performance. ${ }^{1}$ For example, studies consistently show an improvement of driving performance after consuming an energy drink. ${ }^{2,3}$

The negative consequences of the consumption of energy drinks may lead to public concerns about their use. It is important, however, that such concerns are investigated empirically. ${ }^{4,5}$ For example, some authors have argued that mixing alcohol with an energy drink results in increased alcohol consumption and negative alcohol-related consequences. ${ }^{6}$ Research that led to this conclusion has often used a betweengroups comparison, comparing cohorts of subjects who consume AMED with others who consume alcohol only. These papers have demonstrated that AMED consumers differ in many aspects from those who do not consume AMED. For example, AMED consumers are more often males and high risk takers. Hence, they are more often involved in behaviors related to this personality profile, such as alcohol and drug use. ${ }^{6,7}$ It may be incorrect, however, to conclude that the difference in overall alcohol consumption between these groups is caused by mixing alcohol with energy drinks. Using between-groups comparisons, group differences can be identified, but no information is obtained on why these differences are present. To determine if mixing alcohol with energy drinks plays a role in overall alcohol consumption, another research approach is needed. A within-subjects comparison amongst AMED consumers can provide this information. In the same subjects, comparisons are made between the occasions on which they consumed AMED and the occasions on which they only consumed alcohol. This within-subjects approach is regularly used in double-blind, crossover clinical trials, but it can also be used in surveys where participants retrospectively report on occasions when they consumed AMED and occasions when they only consumed alcohol. The biggest advantage of using a within-subjects design is that the same subjects are examined on different occasions, so the study results are not influenced or biased by pre-existing differences between subjects or groups, such as personality characteristics and the level of risk-taking behavior. Recent studies that have adopted this within-subjects design have found no significant or meaningful increases in overall alcohol consumption and its negative consequences when alcohol was mixed with an energy drink. ${ }^{8-12}$ Hence, the presumed negative effects of energy drinks found with between-groups comparisons may not be the result of whether people mix alcohol with an energy drink or not, but the results rather reflect other pre-existing differences between the groups (for example personality differences).
On the other hand, it is possible that there are other reasons why people drink alcohol with energy drinks on some occasions and alcohol alone on others. For example, some people may choose to mix alcohol with energy drinks on occasions when they are fatigued and thus consume less alcohol. The current study thus examined the motives for mixing alcohol with energy drinks.

\section{Motives for energy drink consumption}

Three studies have examined the motives for energy drink consumption when not mixed with alcohol. Attila and Çakir ${ }^{13}$ examined some of the motives of energy drink consumption in 145 Turkish college students. The most frequently reported reason for energy drink consumption was "to feel "energetic", (24.2\%), followed closely by "to boost performance during exercise" (21.4\%), and "for its taste" (17.0\%). To a lesser extent, energy drinks were consumed "to concentrate while studying" $(8.9 \%)$ or "to stay awake". Oteri et al ${ }^{14}$ surveyed 256 Italian students who reported consuming energy drinks. The main motivations for the consumption of energy drinks were "I like it" (67.5\%), "it makes me feel better" (22.1\%), "it makes me to be wide awake until late" (13.0\%), "it helps me in the practice of sport" (13.0\%), and "it helps me in the concentration during study or work" (5.2\%). Malinauskas et al ${ }^{15}$ surveyed 253 American energy drink consumers. The most frequently reported motives for energy drink consumption were "insufficient sleep" (67\%), "to increase energy" (65\%), "while studying or completing major projects" (50\%), "while driving a car for a long period of time"(45\%), and $17 \%$ reported consuming energy drinks to treat a hangover. Taken together, besides the taste, these studies confirm that the most commonly cited motives for the consumption of an energy drink are related to the functional capacities of these drinks - particularly to improve alertness, concentration, and performance.

\section{Motives for consuming alcohol mixed with energy drinks}

Previous studies have reported widely differing prevalence rates of co-ingesting alcohol and energy drinks. For example, Attila and Çakir ${ }^{13}$ reported that $15.2 \%$ of those who consume energy drinks do so to "use in cocktails, mixed with alcohol", while Oteri et $\mathrm{al}^{14}$ reported that $45 \%$ of their sample consumed AMED. Finally, Malinauskas et al ${ }^{15}$ found that $54 \%$ of students who consume energy drinks reported doing so "to drink with alcohol while partying". Although these studies confirm that some of the participants consumed AMED, the researchers did not examine why people do so. Three 
other studies have further examined the possible motives for AMED consumption.

$\mathrm{O}^{\prime}$ Brien et $\mathrm{al}^{16}$ reported that $24 \%$ of their American student sample consumed AMED. About half of AMED consumers reported mixing alcohol with energy drinks to hide the flavor of alcohol (55\%), and $41 \%$ provided a variety of other motives. A minority of students reported negative motives for AMED consumption, such as "to drink more and not feel as drunk" (15\%), to "not get a hangover" $(7 \%)$, or "to drink more and not look as drunk" (5\%). Marczinski surveyed 66 regular energy drink consumers. ${ }^{17}$ Students could score the importance of a number of motives for AMED consumption on a Likert scale ranging from 1 (highly disagree) to 4 (highly agree), around a neutral midpoint (2.5). The most important motives were "like the taste" (3.02), "to celebrate" (3.00), "to socialize" (2.95), and "to get drunk" (2.82). Other motives were considered less important, as indicated by the scores close to or below the neutral midpoint of the scale.

A more recent Australian study by Peacock et al ${ }^{18}$ examined the motives for AMED consumption amongst 403 young adults. The motives were grouped according to different theme areas. Most frequently reported were "hedonistic motives" and "taste and sensation" motives such as "because I like the taste of alcohol and energy drinks together" (69\%) and "because I like the taste of energy drinks" (57\%). Other frequently reported motives were functional motives such as "To feel more energetic" (70\%) and "So I could stay out later" (54\%), or situational motives such as "Because they are the ingredients in a drink (eg, Jägerbomb)" (72\%). With respect to negative motives for AMED consumption, "to get more drunk" was reported by $32 \%$. However, intoxication and impairment related motives such as "so I could drink more" (20\%), "to feel less drunk" (12\%), "to look less drunk" (8\%), and "to avoid getting a hangover" (6\%) were reported by a minority of AMED consumers.

These three studies showed that there are many reasons for mixing alcohol with an energy drink, which can be classified as neutral motives, such as "like the taste", or negative motives such as "to get more drunk". Although these studies suggest that neutral motives are much more frequently reported than negative motives, it is important to investigate the variety of motives in more detail and using a larger sample size. Additionally, the differences in the frequencies of mixing alcohol with energy drinks may result from geographical differences in availability of these drinks, or from differences in accessibility. It is therefore important to examine these effects in different populations - in this case, among Dutch students.

Alcoholic drinks have been mixed with nonalcoholic beverages for decades, if not centuries. A wide range of nonalcoholic beverages have been used for this purpose, including several soft drinks such as colas, tonic water, soda water, ginger ale, as well as all kinds of fruit juices and even cream, milk, cocoa, and coffee. Energy drinks are a relatively new mixer option and up until now, only a few comparisons have been made between energy drinks and other popular mixers such as colas. These studies have shown that people who mix alcohol with energy drinks consume less alcohol than people who mix alcohol with colas. ${ }^{19,20}$ However, these studies had small sample sizes and did not examine the motives for mixing alcohol with specific beverages. Since energy drinks are generally not the first-choice mixer for alcoholic beverages, it is important to determine whether there are specific motives for choosing an energy drink as a mixer, or if these are the same as for other mixers.

It is also of interest to determine whether people who report negative reasons for mixing drinks (for example, "to prevent getting drunk") show increased alcohol consumption on occasions when they consume AMED versus the occasions on which they only consume alcohol. Previous studies from the United States and the Netherlands have shown that AMED consumers as a group, consume comparable amounts of alcohol on AMED occasions and on occasions when they only consume alcohol. ${ }^{8,12}$ It can be hypothesized that this is not the case among people who acknowledge consuming AMED for negative reasons (for example, "To get more drunk"). Up until now, there have been no studies addressing this potentially important research question.

The first aim of the current study was to determine the motives for energy drink consumption, alone or mixed with alcoholic beverages. A second aim was to determine whether negative or neutral motives for consuming AMED have a differential effect on overall alcohol consumption. To examine this, within-subject comparisons on total alcohol consumption were made between occasions on which subjects only consumed alcohol, versus occasions on which they consumed AMED. A third aim was to directly compare alcohol consumption when mixing alcohol with energy drinks and other nonalcoholic beverages.

\section{Methods}

Approximately 70,000 students from the Utrecht University and the Hogeschool of Utrecht in Utrecht, the Netherlands were invited by email to complete the survey. Students 
were included if they were 18-30 years old and provided informed consent. A thorough description of the survey and its methodology is provided elsewhere. ${ }^{11}$ The survey collected demographic data and data on alcohol and energy drink consumption, either consumed alone or mixed, and alcoholrelated negative consequences. Comparing individuals who never drink AMED with AMED consumers may falsely identify relationships that are underscored by a third variable, such as personality traits (for instance, impulsiveness). ${ }^{4,5}$ The survey therefore used a within-subjects design to examine drinking-related variables (ie, comparing - within the same subjects - alcohol consumption on occasions when only alcohol was consumed versus other occasions where alcohol was mixed with an energy drink). ${ }^{6}$

Consumption questions were standardized items that investigated the subjects' consumption habits (frequency and quantity) while considering the particular drink in question, with a focus on beverage consumption within the past 30 days. These questions were adapted from the Quick Drinking Screen. ${ }^{21,22}$ For AMED consumers, the consumption questions were asked separately for occasions on which only alcohol was consumed, and for occasions where alcohol was mixed with energy drinks. To study negative consequences of alcohol consumption, the Dutch version of the Brief Young Adult Alcohol Consequences Questionnaire was completed. ${ }^{23}$ Participants could indicate whether or not any of eleven reasons for energy drink consumption and 13 reasons for mixing alcohol with energy drinks applied to them. The different motives were categorized as negative or neutral according to their presumed effects on total alcohol consumption, as based on previous research. Negative motives were those motives that have been associated with increased alcohol consumption in previous research. All other motives were labeled as neutral, as no effect on the direction of total alcohol consumption could be predicted from previous research.

AMED consumers also answered these questions for other nonalcoholic beverages they mixed with alcohol. Regarding the other nonalcoholic mixers, participants had to choose the one mixer they usually preferred. They had the choice between eight mixers that are popular in the Netherlands, including cola, diet cola, orange-flavored carbonated soft drink, blackcurrant-flavored carbonated soft drink, lemon soda, tonic water, orange juice, and apple juice.

\section{Statistical analyses}

For the current analyses, data from two groups of respondents were considered: participants who consumed energy drinks but never mixed energy drinks with alcohol (energy drinks only group) versus participants who consumed energy drinks and also consumed AMED (AMED group).

The statistical analyses were performed using SPSS version 21 (IBM Corporation, Armonk, NY, USA). Means, standard deviation, and frequency distributions were computed for all variables. To compare demographics, variables with a normal distribution were tested with analysis of variance. For the variables with a binominal distribution, an $X^{2}$ test was performed. The percentage of participants that indicated each motive for energy drink consumption was computed. The same methodology was applied to motives for mixing alcohol with an energy drink or other nonalcoholic beverages. Participants could choose as many motives as applied to them.

Within the AMED group, participants were classified as having neutral or negative reasons for mixing alcohol with an energy drink. Mixing for negative reasons was defined as respondents confirming that they mixed these beverages for at least one of the following reasons: "to get drunk", "to prevent getting drunk", "it feels like I can drink more alcohol", "it feels like energy drinks reduce the negative effects of alcohol", and "to sober up". Although classified as the negative motives group, in parallel these subjects could also have endorsed neutral reasons for mixing. Using paired samples $t$-tests, we determined whether alcohol consumption within the AMED-negative subgroup differed between the occasions on which they only consumed alcohol versus those occasions when they consumed AMED. The differences were considered significant if $P<0.05$.

\section{Results}

From all of the participants who reported consuming energy drinks (number $[\mathrm{N}]=2,329$ ), a total of 1,090 students indicated that they consumed energy drinks, but never mixed them with alcohol. Only around $7.5 \%$ of this group $(\mathrm{N}=173)$ did not consume alcohol at all. The remaining 1,239 students reported mixing alcohol and energy drinks. The demographics of both groups can be found in Table 1 .

\section{Motives for consuming energy drinks (without alcohol)}

The motives for consuming energy drinks (without alcohol) were reported by 2,326 participants and are summarized in Figure 1. The most frequently reported motives were "I like the taste" (reported by $58.6 \%$ of subjects), "To keep me awake" (54.3\%), and "It gives me energy" (44.3\%).

The motives for mixing energy drinks with alcohol were answered by 1,189 AMED consumers. The results are summarized in Table 2. 
Table I Demographics of those who currently only consume energy drinks and those who consume AMED

\begin{tabular}{|c|c|c|c|}
\hline & $\begin{array}{l}\text { Energy drinks only } \\
(\mathrm{N}=\mathrm{I}, 090)\end{array}$ & $\begin{array}{l}\text { AMED } \\
(\mathrm{N}=1,239)\end{array}$ & $P$-value \\
\hline Male/female ratio & $42.2 \% / 57.8 \%$ & $39.1 \% / 60.9 \%$ & $0.005^{*}$ \\
\hline Age (years) & $22.0(2.5)$ & $21.5(2.3)$ & $0.000 *$ \\
\hline Weight (kg) & $71.3(12.5)$ & $70.4(12.2)$ & 0.074 \\
\hline Height (m) & $\mathrm{I} .76(0 . \mathrm{I})$ & I.76 (0.I) & 0.499 \\
\hline $\begin{array}{l}\text { Sorority/fraternity } \\
\text { member }\end{array}$ & $87.2 \%$ & $77.2 \%$ & $0.001 *$ \\
\hline Medication use & $17.9 \%$ & $23.0 \%$ & 0.159 \\
\hline Drug use & $5.2 \%$ & $38.3 \%$ & $0.000 *$ \\
\hline Tobacco use & $5.2 \%$ & $20.3 \%$ & $0.000 *$ \\
\hline
\end{tabular}

Notes: Mean (SD) values are shown. *Significant differences $(P<0.05)$ between the groups.

Abbreviations: AMED, alcohol mixed with energy drinks; N, number; SD, standard deviation.

The majority of students consumed AMED for neutral motives $(78.4 \%)$. By far, the most frequently cited motive for consuming AMED (81.1\%) was "I like the taste", followed by "I wanted to drink something else" (35.3\%), and "To celebrate a special occasion, party" (14.6\%). As is evident from Table 2, negative motives for consuming AMED were reported by relatively fewer students. That is, $21.6 \%(\mathrm{~N}=257)$ of students reported consuming AMED for at least one of the five negative motives listed in Table 2.

\section{Negative motives for mixing alcohol with energy drinks}

A specific group of interest were 257 subjects who indicated mixing alcohol with energy drinks for at least one of the five negative motives, as listed in Table 2 . When comparing these individuals with those who consume AMED for neutral motives, several differences between the groups could be noted, and these are summarized in Table 3. For example, those who consume AMED for negative motives are significantly more often males, use more drugs and tobacco, and experience more negative alcohol-related consequences.

To determine whether those who consume AMED for negative motives consume more alcohol on occasions when they mix alcohol with energy drinks when compared to those occasions on which they only consume alcohol, within-subjects comparisons were conducted. The results are summarized in Figure 2.

Figure 2 shows that despite the fact that these subjects consumed AMED for negative motives, on the occasions when they drank AMED, they consumed significantly less alcohol and were drunk less often when compared to those occasions on which they only consumed alcohol. Moreover, they experienced significantly less $(P<0.0001)$ negative alcohol-related consequences when consuming

Reasons for drinking ED (without alcohol), percentage "yes" of $\mathrm{N}=2,326$

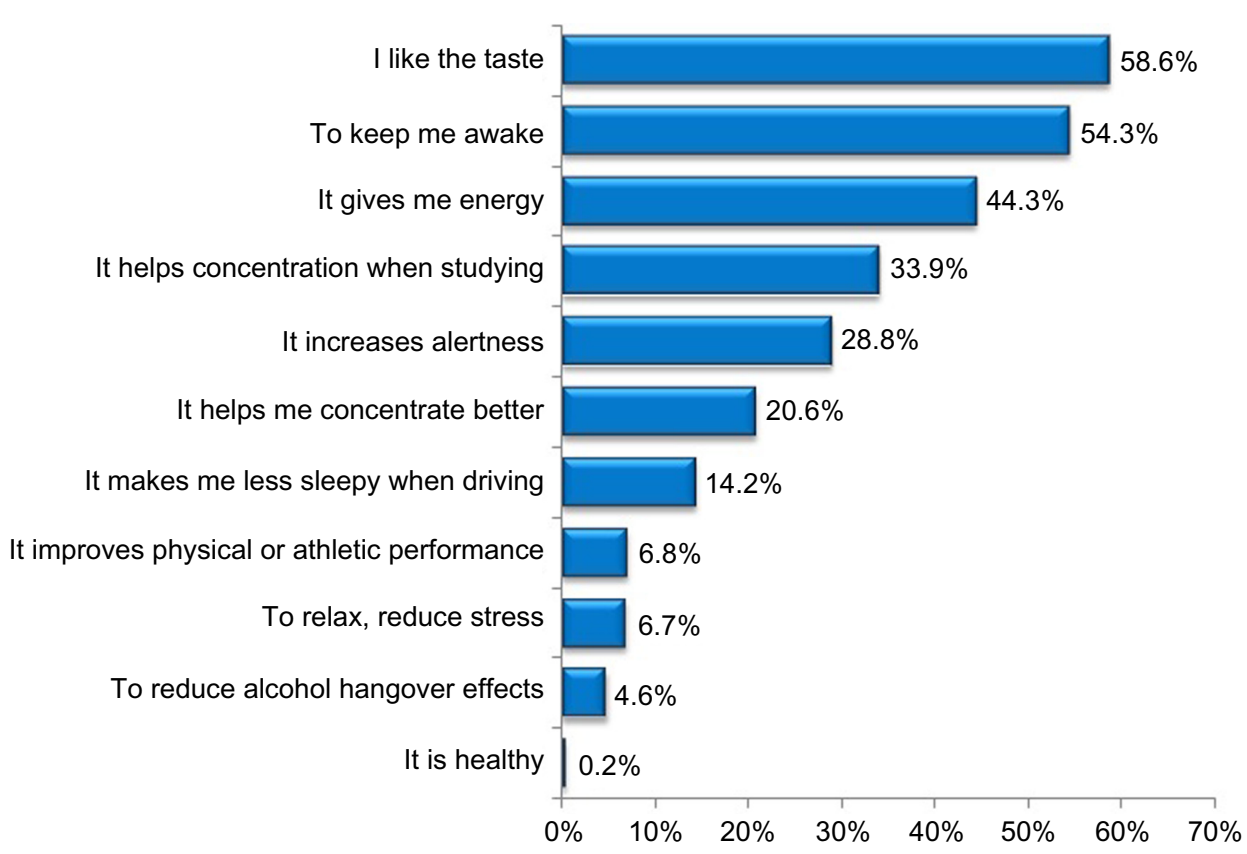

Figure I Reasons for ED consumption (without alcohol) reported by $\mathrm{N}=2,326$ respondents. Abbreviations: $\mathrm{ED}$, energy drinks; $\mathrm{N}$, number. 
Table 2 Endorsement of neutral and negative motives for mixing alcohol with energy drinks or other nonalcoholic beverages among AMED consumers $(\mathrm{N}=\mathrm{I}, 189)$

\begin{tabular}{lll}
\hline Neutral motives for mixing with & $\begin{array}{l}\text { Energy } \\
\text { drink }\end{array}$ & $\begin{array}{l}\text { Other } \\
\text { beverages }\end{array}$ \\
\hline I like the taste & $81.1 \%$ & $90.2 \% *$ \\
I wanted to drink something else & $35.3 \%$ & $42.6 \%$ \\
To celebrate a special occasion, party & $14.6 \%$ & $14.9 \%$ \\
I got the drink from someone (and did & $7.0 \%$ & $6.8 \%$ \\
not want to refuse it) & & \\
To make me happy & $5.0 \%$ & $5.2 \%$ \\
Because others drink it as well & $4.8 \%$ & $4.7 \%$ \\
To reduce next-day hangover effects & $2.4 \%$ & $5.6 \% *$ \\
I felt sad & $0.3 \%$ & $0.3 \%$ \\
Negative motives for mixing with & Energy & Other \\
\hline To get drunk & drink & beverages \\
It feels like it reduces the negative & $8.0 \%$ & $10.9 \% *$ \\
effects of alcohol & $6.9 \%$ & $5.1 \%$ \\
It feels like I can drink more alcohol & $5.6 \%$ & $6.5 \%$ \\
To prevent getting drunk & $3.8 \%$ & $9.0 \% *$ \\
To sober up & $2.9 \%$ & $6.0 \% *$ \\
\hline Not & &
\end{tabular}

Note: *Significant differences $(P<0.05)$.

Abbreviations: AMED, alcohol mixed with energy drinks; $N$, number.

AMED (3.8), as compared to those occasions on which they only consumed alcohol (6.5).

\section{Comparison with other mixers}

The motives for consuming alcohol with other mixers were in line with those reported for mixing with energy drinks (see Table 2). For some of the motives, a statistically significant difference was found between energy

Table 3 Comparison of subjects who consume AMED for negative and neutral motives

\begin{tabular}{llll}
\hline & $\begin{array}{l}\text { Mixing for } \\
\text { negative } \\
\text { motives } \\
\mathbf{( N = 2 5 7 )}\end{array}$ & $\begin{array}{l}\text { Mixing for } \\
\text { neutral } \\
\text { motives } \\
\mathbf{( N = 9 8 2 )}\end{array}$ & P-value \\
\hline Male/female ratio & $53.7 \% / 46.3 \%$ & $35.2 \% / 64.8 \%$ & $0.000^{*}$ \\
Age (years) & $21.6(2.3)$ & $21.5(2.4)$ & 0.512 \\
Weight $(\mathrm{kg})$ & $72.3(11.4)$ & $69.9(12.4)$ & $0.005^{*}$ \\
Height $(\mathrm{m})$ & $1.77(0.1)$ & $1.76(0.1)$ & $0.028^{*}$ \\
Sorority/fraternity member & $26.8 \%$ & $21.7 \%$ & 0.078 \\
Medication use & $18.3 \%$ & $24.2 \%$ & $0.025^{*}$ \\
Drug use & $51.8 \%$ & $34.8 \%$ & $0.000^{*}$ \\
Tobacco use & $51.0 \%$ & $29.3 \%$ & $0.003^{*}$ \\
BYAACQ score when not & $6.5(4.0)$ & $4.5(3.6)$ & $0.000^{*}$ \\
mixing & & & \\
BYAACQ score when & $3.8(3.5)$ & $2.3(3.4)$ & $0.000^{*}$ \\
consuming AMED & & & \\
\hline
\end{tabular}

Notes: Mean (SD) values are shown. *Significant differences $(P<0.05)$ between the groups.

Abbreviations: AMED, alcohol mixed with energy drinks; N, number; BYAACQ, Brief Young Adult Alcohol Consequences Questionnaire; SD, standard deviation. drinks and other nonalcoholic mixers. Notably, more subjects endorsed negative motives for other mixers when compared to energy drinks. However, these items were indicated by only a small number of subjects, and the differences therefore may not have any practical relevance. Alcohol consumption patterns, when mixing with energy drinks and other nonalcoholic beverages, also did not show any relevant differences (see Table 4).

\section{Discussion}

This study shows that motives for the consumption of energy drinks are mainly driven by consumers' appreciation of their taste, and expectations regarding the positive effects of the drinks' functional ingredients (ie, to improve alertness, concentration, and performance). The motives for mixing alcohol with energy drinks or other nonalcoholic beverages are comparable. The most frequently reported motives were of a neutral nature, such as liking the taste, celebrating a special occasion, or wanting to consume something else. A minority of students (21.6\%) also reported one or more negative motives for consuming AMED. Within-subjects comparisons showed, however, that these subjects' overall alcohol consumption was significantly lower on occasions when they consumed AMED, as compared with occasions when they only consumed alcohol. These findings are consistent with those found for students who consumed AMED for neutral reasons ( $78.4 \%$ of the sample). It is important to acknowledge that the widespread belief that mixing alcohol with energy drinks may enhance alcohol consumption is not supported by the views of the consumers themselves, since only a small minority reported that "It feels like I can drink more alcohol" (5.6\%).

Taken together, this study shows that a minority of students have negative motives for AMED consumption. However, this does not differentially affect their total alcohol intake in comparison to students who consume AMED for neutral reasons. For both groups, overall alcohol consumption is significantly reduced when mixing alcohol with an energy drink, as compared to the occasions on which they consumed alcohol only. Also, no relevant differences in alcohol consumption were found between the occasions when alcohol was mixed with an energy drink, or when it was mixed with other nonalcoholic beverages. These findings suggest that energy drinks are not unique or different from the many other mixers that consumers can choose from.

Our results are in line with the results from previous research on the motives for mixing alcohol with energy drinks. ${ }^{15-18}$ One strength of our paper relative to the previous 


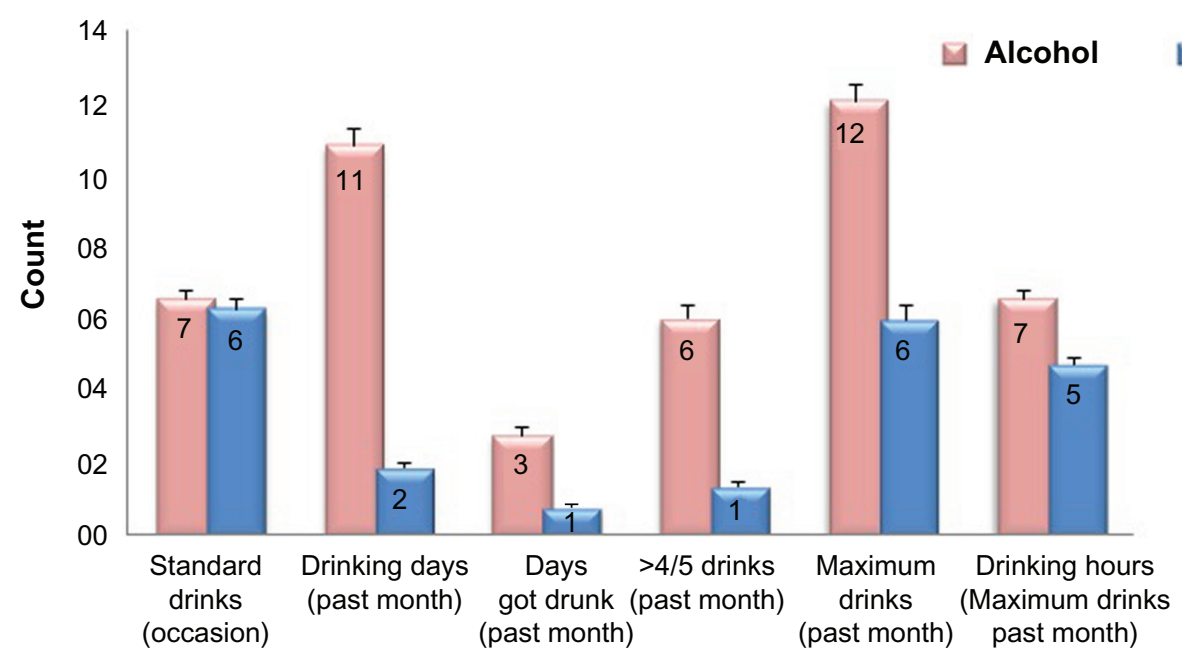

Figure 2 Within-subjects comparison of drinking behavior of $\mathrm{N}=257$ subjects who consumed AMED for negative motives. Note: Occasions when they consumed AMED are compared with the occasions when they only consumed alcohol. Abbreviations: AMED, alcohol mixed with energy drinks; N, number.

studies is its large sample size. Further, our study clearly distinguishes between neutral and negative motives. Finally, this is the first study to make a direct comparison between the motives for consuming alcohol with an energy drink and those for consuming other nonalcoholic mixers.

In contrast to many previous studies, our analyses comprised within-subjects comparisons. This is an advantage over between-group comparisons, which are likely to be biased if one accepts that AMED consumers differ in terms of many demographic and personality variables when compared to those who do not consume AMED. Within-subjects comparisons focussed on AMED consumers, only allowing the

Table 4 Alcohol consumption among AMED consumers when they only consumed alcohol, AMED, or alcohol mixed with other nonalcoholic beverages (other mixers)

\begin{tabular}{|c|c|c|c|}
\hline $\begin{array}{l}\text { Alcohol consumption among } \\
\text { AMED consumers }(\mathrm{N}=1,239)\end{array}$ & $\begin{array}{l}\text { Alcohol } \\
\text { only }\end{array}$ & AMED & $\begin{array}{l}\text { Other } \\
\text { mixers }\end{array}$ \\
\hline $\begin{array}{l}\text { How many standard drinks do you } \\
\text { usually have on one occasion? }\end{array}$ & $6.0(3.9)$ & $5.4(3.7)$ & $5.1(3.6)$ \\
\hline How many days did you drink alcohol? & $9.2(6.4)$ & $1.4(1.8)$ & $2.5(2.9)$ \\
\hline How many days did you get drunk? & $\mathrm{I} .9(2.7)$ & $0.5(1.0)$ & $0.8(1.4)$ \\
\hline $\begin{array}{l}\text { How many times did you have more } \\
\text { than five (males)/four (females) } \\
\text { alcoholic drinks on one occasion? }\end{array}$ & 4.8( & $0.9(1.7)$ & $1.5(2.5)$ \\
\hline $\begin{array}{l}\text { What is the greatest number of } \\
\text { alcoholic drinks you had on one } \\
\text { occasion? }\end{array}$ & $10.7(6.7)$ & $4.5(5.7)$ & $5.4(5.7)$ \\
\hline $\begin{array}{l}\text { On that occasion (previous question), } \\
\text { how many hours did you consume } \\
\text { alcohol? }\end{array}$ & $6.0(3.1)$ & $4.0(3.3)$ & $4.4(2.9)$ \\
\hline
\end{tabular}

Notes: Questions were answered for the past 30 days. All pairwise comparisons between alcohol only, AMED, and other mixers were statistically significant $(P<0.05)$. Data are presented as mean and standard deviation. Abbreviations: AMED, alcohol mixed with energy drinks; $N$, number. comparison of alcohol consumption variables within the same subjects on two different occasions: those on which alcohol is mixed with energy drink, and those when the same subjects consume alcohol only. This way, we were able to determine if an observed difference was related to the coconsumption of an energy drink (or not).

It is important to note that the observed differences between the groups who consumed AMED for negative rather than neutral motives (Table 3 ) could not be attributed to energy drink consumption, since both groups consisted of AMED consumers.

Our survey has some limitations. As was the case in previous research, we asked participants whether each motive applied to AMED consumers or not. However, we gathered no information about the relative importance of each motive, nor did we investigate how often each motive was important. It may be that some motives are important on one occasion, but not on another (for example, during a wild party versus a regular visit to the pub). Additionally, we cannot preclude the possibility that there may be a selection bias, with individuals who are pro- (or indeed anti-) energy drinks being more likely to complete the survey. It is also worth pointing out that the responses to certain questions such as, "How many days did you get drunk?" are necessarily influenced by the higher number of occasions when individuals only consumed alcohol compared with AMED. Indeed, if we examine the number of days on which respondents indicated that they got drunk as a proportion of the number of days that they consumed each type of drink, we find that this occurred $21 \%$ of the time on occasions when they only consumed alcohol, and $36 \%$ and $32 \%$ of the time when consuming 
AMED and alcohol with other mixers, respectively. Thus, on the few occasions where these people used a mixer (energy drink or another nonalcoholic beverage), they tended to get drunk more often. These relationships may merit further exploration.

These data reveal that subjects had many more alcoholonly days than days on which they consumed AMED. It is unknown how many of the total drinking days were heavy drinking days (ie, close to the maximum monthly number of drinks) and how many were "normal" drinking days (ie, one drink with dinner). Although there is information on the number of days spent intoxicated and the number of days on which more than 4-5 alcoholic drinks were consumed, including these values in the statistical analysis would result in speculative interpretation of the data, because we can only guess as to whether subjects had negative or neutral motives on each of these days. One conclusion supported by our data is that people consume less alcohol when they mix alcohol with energy drinks, both on average drinking days and on their maximum heavy drinking occasions, irrespective of their motives for mixing.

Another limitation that is by no means specific to this study is the reliance on people to remember the number/type of drinks consumed when intoxicated (although there is no reason to assume that this should differ when recollecting AMED compared with alcohol-alone occasions). Finally, the data were collected among students in the Netherlands. To determine whether cross-cultural differences in motives for mixing exist, our survey is currently being replicated in Australia and the United Kingdom.

\section{Conclusion}

In conclusion, we did not observe relevant differences in individuals' motivations for mixing alcohol with an energy drink and their motivations to mix alcohol with other nonalcoholic beverages. It is worth emphasizing that the majority of students who participated in the survey consumed alcohol at levels substantially higher than the current guidelines for safe consumption, independent of the motives they had for mixing alcohol with energy drinks or other beverages, and irrespective of whether alcohol was mixed with other beverages or not.

\section{Acknowledgments}

This survey was supported by a grant from Red Bull GmbH. Red Bull GmbH was not involved in the design and conduct of the study, collection, management, analysis, interpretation of the data, or preparation of the manuscript.

\section{Disclosure}

Joris C Verster has received grants/research support from The Dutch Ministry of Infrastructure and the Environment, Takeda, and Red Bull; has acted as a consultant for the Canadian Beverage Association, Centraal Bureau Drogisterijbedrijven, Coleman Frost, Deenox, INSV, Purdue, Red Bull GmbH, Sanofi-Aventis, Sepracor, Takeda, Transcept, and the Trimbos Institute. Andrew Scholey has held research grants from Bayer HealthCare, Cognis, Cyvex, GlaxoSmithKline, Naturex, Nestlé, Martek, Masterfoods, Wrigley, and has acted as a consultant/expert advisor to Abbott Nutrition, Barilla, Bayer HealthCare, Danone, Flordis, GlaxoSmithKline Healthcare, Masterfoods, Martek, Novartis, Unilever, and Wrigley. Sarah Benson reports no conflicts of interest in this work.

\section{References}

1. Scholey AB, Kennedy DO. Cognitive and physiological effects of an "energy drink": an evaluation of the whole drink and of glucose, caffeine and herbal flavouring fractions. Psychopharmacology (Berl). 2004;176(3-4):320-330.

2. Mets MA, Ketzer S, Blom C, et al. Positive effects of Red Bull ${ }^{\circledR}$ Energy Drink on driving performance during prolonged driving. Psychopharmacology (Berl). 2011;214(3):737-745.

3. Alford C, Cox H, Wescott R. The effects of red bull energy drink on human performance and mood. Amino Acids. 2001;21(2):139-150.

4. Verster JC, Alford C. Unjustified concerns about energy drinks. Curr Drug Abuse Rev. 2011;4(1):1-3.

5. Verster JC, Aufricht C, Alford C. Energy drinks mixed with alcohol: misconceptions, myths, and facts. Int J Gen Med. 2012;5:187-198.

6. Berger LK, Fendrich M, Chen HY, Arria AM, Cisler RA. Sociodemographic correlates of energy drink consumption with and without alcohol: results of a community survey. Addict Behav. 2011;36(5):516-519.

7. Snipes DJ, Benotsch EG. High-risk cocktails and high-risk sex: examining the relation between alcohol mixed with energy drink consumption, sexual behavior, and drug use in college students. Addict Behav. 2013;38(1):1418-1423.

8. Woolsey C, Waigandt A, Beck NC. Athletes and energy drinks: reported risk-taking and consequences from the combined use of alcohol and energy drinks. J Appl Sport Psychol. 2010;22(1):65-71.

9. Peacock A, Bruno R, Martin FH. The subjective physiological, psychological, and behavioral risk-taking consequences of alcohol and energy drink co-ingestion. Alcohol Clin Exp Res. 2012;36(11): 2008-2015.

10. Brache K, Stockwell T. Drinking patterns and risk behaviors associated with combined alcohol and energy drink consumption in college drinkers. Addict Behav. 2011;36(12):1133-1140.

11. de Haan L, de Haan HA, Olivier B, Verster JC. Alcohol mixed with energy drinks: methodology and design of the Utrecht Student Survey. Int J Gen Med. 2012;5:889-898.

12. de Haan L, de Haan HA, van der Palen J, Olivier B, Verster JC. Effects of consuming alcohol mixed with energy drinks versus consuming alcohol only on overall alcohol consumption and negative alcohol-related consequences. Int J Gen Med. 2012;5:953-960.

13. Attila S, Çakir B. Energy-drink consumption in college students and associated factors. Nutrition. 2011;27(3):316-322.

14. Oteri A, Salvo F, Caputi AP, Calapai G. Intake of energy drinks in association with alcoholic beverages in a cohort of students of the School of Medicine of the University of Messina. Alcohol Clin Exp Res. 2007;31(10):1677-1680. 
15. Malinauskas BM, Aeby VG, Overton RF, Carpenter-Aeby T, Barber-Heidal K. A survey of energy drink consumption patterns among college students. Nutr J. 2007;6:35.

16. O'Brien MC, McCoy TP, Rhodes SD, Wagoner A, Wolfson M. Caffeinated cocktails: energy drink consumption, high-risk drinking, and alcohol-related consequences among college students. Acad Emerg Med. 2008;15(5):453-460.

17. Marczinski CA. Alcohol mixed with energy drinks: consumption patterns and motivations for use in US college students. Int J Environ Res Public Health. 2011;8(8):3232-3245.

18. Peacock A, Bruno R, Martin FH. Patterns of use and motivations for consuming alcohol mixed with energy drinks. Psychol Addict Behav. 2013;27(1):202-206.

19. Thombs D, Rossheim M, Barnett TE, Weiler RM, Moorhouse MD, Coleman BN. Is there a misplaced focus on AmED? Associations between caffeine mixers and bar patron intoxication. Drug Alcohol Depend. 2011;116(1-3):31-36.
20. Penning R, de Haan L, Verster JC. Caffeinated drinks, alcohol consumption, and hangover severity. Open Neuropsychopharmacol J. $2011 ; 4: 36-39$

21. Sobell LC, Agrawal S, Sobell MB, et al. Comparison of a quick drinking screen with the timeline followback for individuals with alcohol problems. J Stud Alcohol. 2003;64(6):858-861.

22. Roy M, Dum M, Sobell LC, et al. Comparison of the quick drinking screen and the alcohol timeline followback with outpatient alcohol abusers. Subst Use Misuse. 2008;43(14):2116-2123.

23. Verster JC, van Herwijnen J, Olivier B, Kahler CW. Validation of the Dutch version of the brief young adult alcohol consequences questionnaire (B-YAACQ). Addict Behav. 2009;34(5):411-414.
International Journal of General Medicine

\section{Publish your work in this journal}

The International Journal of General Medicine is an international, peer-reviewed open-access journal that focuses on general and internal medicine, pathogenesis, epidemiology, diagnosis, monitoring and treatment protocols. The journal is characterized by the rapid reporting of reviews, original research and clinical studies across all disease areas.

\section{Dovepress}

A key focus is the elucidation of disease processes and management protocols resulting in improved outcomes for the patient.The manuscript management system is completely online and includes a very quick and fair peer-review system. Visit http://www.dovepress.com/ testimonials.php to read real quotes from published authors.

Submit your manuscript here: http://www.dovepress.com/international-journal-of-general-medicine-journal 